Mariano Latorre.

\title{
EL SENTIDO DE LA NATURALEZA EN LA POESIA CHILENA
}

SCAR LANAS es su reverso (1). Si Echeverría soñó el mar como un vidente y su experiencia marítima es la aguda comprensión de las ásperas narraciones de su padre, Lanas recogió en diez años de correrías por la costa del Pacífico sus aguas fuertes del Océano. Espuma y humo de carbón, traqueteo de máquinas y graznidos de pájaros, rojas auroras y noches plateadas, gritos de marineros ebrios y trágicas peleas en las cantinas de los puertos, supersticiones ocultas como monstruos en la caverna de las máquinas o en las mal olientes bodegas de los buques, forman el dinámico tumulto de sus versos marítimos. Dinámico él también, piloto de vapores caleteros o sobrecargo en transatlánticos ingleses, vagabundo en Haway o desertor en Panamá, barretero más tarde en la pampa o repórter de periódicos en el Perú o en Colombia, Oscar Lanas pasea su verbosidad pintoresca por toda la América. Agil, mentiroso como un andaluz, agitada siempre su cabellera criolla de negros rizos de alquitrán por un invisible viento aventurero. Poeta, sobre todo. Hace diez años que intenta publicar un libro y no consigue reunir sus versos que ruedan, como un polen poético, por todas las redacciones de los diarios santiaguinos.

El libro se inicia con un pórtico lírico, que habla de un imaginario nacimiento náutico: canción del navinato o el nacido en la nave:

¡Yo he nacido en el mar! ¡Yo he nacido en el mar! y en un claro día de primavera.

Los hombres siempre nacen en seguro solar.

(1) El autor se refiere a don Raimundo Echeverría y Larrazábal. Véase el número anterior de ATENEA, en que se publicó la primera parte de este estudio. 
Yo he nacido en un barco, lejos de la ribera.

Un marinero viejo, al irme a bautizar

-dicen-ungió mis labios con el agua salobre.

$\mathrm{Y}$ yo, frente a la vida, poniéndome a pensar, no siento la tristeza de haber nacido pobre, porque nací en el Mar, porque nací en el Mar.

Mis pulmones llenáronse con la esencia salina y el viento en mis oídos sopló su caracol. Una nube fantástica me sirvió de madrina $y$ de padrino el sol.

Hubo fiestas a bordo. Fuegos artificiales de fantasmagorías debajo de mi cuna.

Los truenos descargaron gruesas artillerías.

De oro era el farol chinesco de la luna, y de plata la bandeja del agua, llena de pedrerías.

¿Qué más honor? ¿Qué príncipe tuvo lo que yo tuve?

Naciendo en cunas de oro jamás podrán contar con el nevado alcázar que yo tengo en la nube, ni la vasta comarca que poseo en el mar.

Soy hijo del Océano. Lo amo, como él me quiere.

Mi espíritu es el alma de su harmonium profundo.

A veces manso y suave, cual la ola que muere,

y otras veces, cual tromba de empuje furibundo.

Soy único heredero del amplio mar sonoro.

¡Qué de riquezas guardo bajo su espeso tul!

Pero yo sé la clave de sus puertas de oro,

pues soy un pensamiento de su cerebro azul.

Más adelante canta al lobo de mar y en su vagabunda psicología pone algo de su propio espíritu.

Viejo lobo marino que enciendes tus pupilas con las maravillosas visiones de tu andanza, en tanto de tu pipa se elevan intranquilas volutas que semejan un barco en lontananza. La llama de los vientos doró tu piel de lobo, lo mismo que los soles que inciensan los racimos, buscando inmensidades atravesaste el globo, pues siempre fué mezquina la playa en que nacimos.

El humor marinero retoza en un dibujo al carbón, apenas esbozado, sin título, con un musical de barcarola, que el poeta anota en la forma siguiente:

Vaivén en una noche, a bordo de un vapor anclado en un puerto oscuro, mientras el piloto está durmiendo sobre el coy y la luz de la luna que va asomando, le alumbra el rostro. 
¡Eh! Contramaestre

que tienes tu panza

como tu barca.

Cuando caminas

llevas el mismo

ritmo del agua.

Gimen los mástiles,

chillan los pinos,

pifian las tablas,

y los baupreses

indican rutas

imaginarias.

$\mathrm{La}$ vela se infla como la enagua

de una preñada.

$\mathrm{Y}$ desde tierra

los mandoleones

lloran nostalgias.

Las mariposas

de las pavesas

saltan y saltan, saltan y saltan.

$Y$ las gaviotas

como albas flechas

pican el agua.

$\mathrm{Y}$ las gaviotas,

como pañuelos

de despedida

baten el agua.

Los horizontes

cierran sus puertas

con nubes raras,

$y$ al sol le sangra,

tal como a un Cristo,

toda la cara.

El viento rasga

sus vestiduras

entre las gavias,

y tu recuerdo

rompe mi frente

como cascada.

La luna trepa

- araña de oro-

por las escalas,

$y$ en unas nubes

fija sus finos

hilos de plata.

A veces, mira

la claraboya

que da en mi cara,

y mientras duermo

como un grumete,

balanceándome

sobre la hamaca,

ella derrama,

toda la noche, toda la noche, toda la noche, 
natas de luces

sobre las aguas, sobre las aguas, sobre las aguas.

Alejandro Reyes y Víctor Barberis, si no han navegado mucho, han sentido, en cambio, la nostalgia del velero que arriba de alta mar, oliente a aceite de ballena y decorado por arabescos de sal, la poesía de las redes, puñados de rectas grises, sujetas al suelo por fragantes estacas de boldo, o los viejos lanchones de la rada, barnizados de costeñas garúas, cuyas proas gastadas cortan los ángulos de las bodegas o se enredan, como pesadas arañas, en la red enhollinada de las grúas.

Todos sus recuerdos de niño y adolescente los ha fijado Alejandro Reyes en Motivos del Puerto. Revive el antiguo Talcahuano en sus sonetos, de vigoroso diseño y delicados tonos de color: los rincones de la bahía, sus coloniales pescadores, sus prácticos, sus capitanes y sus astilleros, sus laboriosos remolcadores, envueltos en humo; los veleros de velas grises como las alas de las gaviotas viejas; el estruendo de las mareas invernales o la modorra de la histórica bahía, ebria de azul en las siestas del estío.

\section{LA RIA}

El canal tiene un ambiente de paisajito holandés...

Llevado por la corriente

un lanchón nada al revés.

Son dos manchas de colores las orillas de la ría: casitas de pescadores le prestan su poesía.

$\mathrm{Y}$ horadando la calvicie de una escueta superficie, en una pirueta gráfica

que contra el cielo arremete, se levanta el estilete de la antena telegráfica.

\section{PUERTO VIEJO}

Vuestro encanto de antaño, viejos barcos veleros, avezadas fragatas y gallardas goletas, ágiles bergantines y balandros ligeros, mecidos blandamente sobre las aguas quietas.

Ya no se ve la gracia de vuestros masteleros, ni el mascarón de proa sonreír al oleaje, ni tampoco se escuchan cantares marineros salir desde la recia trama de los cordajes. 
Y ya apenas si llegan, al par de la marea,

esas brisas salinas, con hálitos de brea,

que aspiramos de niños, junto a la vieja rada...

\begin{abstract}
Humos, «donkeys», vapores, en un conjunto ambiguo.
$Y$ ya, en el puerto viejo, de vuestro encanto antiguo, no va quedando nada, no va quedando nada!...
\end{abstract}

Llegamos por último, a la más reciente modalidad de nuestra poesía, en su relación con la naturaleza chilena.

Una honda huella de los paisajes del norte, del centro y del sur se observa en los poetas modernos. El esfuerzo iniciado por los primeros intérpretes de la náturaleza chilena ha producido sus frutos. Ahora el color está en una palabra, en una breve acotación, en el trazo de un árbol, de una montaña o de un tronco que voltea río abajo, pero la composición cerebral predomina sobre la individualización de las cosas. El tono luminoso no es lo principal. Es lo accesorio; y sin embargo, es lo distintivo, lo que da a estos poetas, a pesar de sus influencias extranjeras, un carácter nacional.

Algunos, que he colocado en las clasificaciones anteriores, pueden caber asimismo en esta última etapa de poesía pura, quinta-esenciada: Magallanes Moure, por ejemplo, pero esto se debe a la evolución del poeta a través de todas las etapas, incluso la modernista, mientras otros se han detenido en un momento dado de esa evolución. En el carácter estilizado de todos estos poetas últimos, es fácil reconocer, por sus metáforas, la zona de Chile donde nacieron o vivieron.

Mondaca y Gabriela Mistral tienen una raíz común de atormentada inquietud mística. Ya hemos hablado de la influencia religiosa de La Serena. Debemos agregar aún el ensueño angustiante del minero del norte que busca durante años una veta y no la encuentra. En Coquimbo casi todos son mineros o poseedores de una pertenencia no explotada. Luego, la trágica alarma de los piratas de la colonia, que llegaban a la región en busca de criollas de ojos ardientes y de las sabrosas frutas de los huertos, quebró la quietud de aquellas almas y les dió un motivo de miedo o de peligro vago que fué en el tiempo germen de fantasía creadora.

El ambiente cultivado de la capital ha dado poetas sabios, de gustos cortesanos, como Hübner, Ernesto Guzmán y sobre todo, Préndez Saldías, en contraposición al arte juglaresco, eglógico de Jorge González y Carlos Acuña. Esta nota cerebral se acentúa en los innovadores, hijos de Europa, Pablo de Rokha y Pablo Neruda. La cordillera de la costa desempeña también 
un papel importante en la evolución nacionalista de nuestra lírica. Además de Jorge González tiene un intérprete de sus paisajes gredosos, de sus leyendas y de sus huasos sencillos, en Max Jara. Verleniano en sus primeros tiempos, hosco y angustiado, se purifica como un agua de vertiente en la primavera y nos da en romances, a la manera de los poetas españoles del siglo XV, una visión nueva, esencial, de las tierras pobres y su tragedia.

Carlos Mondaca era de Vicuña, vieja ciudad de la provincia de Coquimbo. Se educó en el Seminario de La Serena. Esta educación piadosa, casi la de un aspirante a sacerdote, imprimió una huella nunca borrada en su sensibilidad de niño y de hombre. Bondad húmeda, cristiano altruísmo por seres y cosas, que fué acentuándose paulatinamente hasta convertirse en su manera de ser, en su filosofía, en la esencia misma de su personalidad literaria.

Sus versos son una flor de cultura, una concreción armoniosa de su bondad y de su comprensión del problema de la vida. No escribió versos porque sí. Estos nacían cuando la copa desbordaba, cuando la saturación poética rompía la costra de materialidad que la vida cotidiana había dejado en é!. La naturaleza aparece en sus versos, pero alejada, como una nota de color, del recuerdo de un color, para exteriorizar este mundo interno, estas moradas, donde el poeta se ha recogido a contemplar la vida. La madre, la esposa, los hijos: hogar humano. Cristo y la Virgen: hogar supraterreno.

Esta visión estilizada de la naturaleza donde ya no se precisa la sensación visual, porque en el cerebro del poeta se ha acendrado, haciéndose un toque vago, podemos verlo en un fragmento de su poesía Cuando el Señor me hlame:

Una mañana de abril-habrá llovidono me levantaré. Se acercarán sin ruido las gentes de mi casa para observar si duermo y por sus ojos tristes sabré que estoy enfermo. El temblor de sus lágrimas será la estrella que me diga que es preciso partir y no volver; y como para entonces estaré tan cansado, no haré siquiera un gesto de espera. Resignado no pediré otra cosa que entreabran la ventana para mirar el cielo; y hasta mi frente cana descenderá piadosa y azul la caridad de la mañana, a darme la postrer claridad. Estaré con los ojos cerrados, como inerte, saboreando la última tregua de la muerte.

De vez en vez, sus manos, santas y dolorosas, mi mujer pondrá en mí con suavidad de rosas. 
Mi hijo me mirará callada y largamente - los labios de su madre se han posado en mi frente-, y como teme que me turben sus sollozos, se abrazará a mi nuera. Con sus ojos curiosos que lloran y no saben, pregunta el nieto. Cae la tarde lentamente. Rumor de otoño trae la brisa, quejas de árboles y la melancolía de lejanas campanas vesperales. El día se irá junto conmigo.

Sobre Gabriela Mistral se ha escrito mucho y casi siempre desacertado. Cierta entonación bíblica de sus versos, tal vez su carácter de maestra, han sugerido la fácil asociación del origen hebreo de su poesía, de su parentesco con las parábolas del Nuevo Testamento. Nada de eso en mi concepto. La psicología de Gabriela Mistral no tiene tales complicaciones. Es una mujer atormentada que ha convertido en un ascetismo espiritual sus muy humanas ansias de amar. Hay en el enredo de una sintaxis primitiva. sin mucha ciencia, destellos de luz, extrañas y retorcidas metáforas que por lo mismo resaltan más. Así brilla en mil destellos un diamante destrozado, si la gracia del sol se disuelve en sus minúsculas aristas. Vale decir, en este caso, verdadera, humana y muy chilena emoción de Gabriela Mistral.

A un temperamento tan generosamente dotado de sensaciones como el de nuestra poetisa, la naturaleza de Chile no podía serle indiferente. Así, esta agria potencia antropomórfica de la artista ha convertido en símbolos los árboles quemados por las nevascas patagónicas y por los vientos glaciales que lo modelaron a su antojo. Arboles quemados o espinos enloquecidos de sed en tierras muertas, en laderas de rojo corazón de greda. Ved su Arbol Muerto, de pie en la desolación de la llanura:

En el medio del llano, un árbol seco su blasfemia alarga;

un árbol blanco, roto y mordido de llagas, en el que el viento, vuelto mi desesperación, aúlla y pasa.

De su voz que ardió, sólo dejaron, de escarnio, su fantasma.

Una llama alcanzó hasta su costado y lo la mió, como el amor mi alma.

$\mathrm{Y}$ sube de la herida, un purpurino musgo, como una estrofa ensangrentada.

Los que amó, y que ceñían

a su torno en Setiembre una guirnalda,

cayeron. Sus raíces

los buscan, torturadas,

tanteando por el césped, 
con una angustia humana.

Le dan los plenilunios en el llano

sus más mortales platas,

y alargan, porque mida su amargura,

hasta lejos su sombra desolada.

$\mathrm{Y}$ él le da al pasajero

su atroz blasfemia y su visión amarga.

En nadie esta inquietud de vivir, inquietud que es casi una alucinación, se ha cristalizado mejor que en la poetisa María Peralta, de Elqui, muerta a los veinte años. Cuerpo quebradizo que el amor y la tisis abrasaron en afiebrados estremecimientos. Un terror ancestral viene de otros siglos a posesionarse de ella. Un barco pirata ha arriado sus velas obscuras junto a su corazón. En sus versos simples, hechos de pavor y esperanzas, de vida y de muerte, revive estilizada, hecha poesía, la vieja leyenda de bucaneros que las abuelas trasmitieron de generación en generación, al borde del brasero de bronce y entre chupada y chupada de la tradicional bombilla de plata y del cigarrillo de hoja de maíz.

Así es su Barca Negra:

La barca, la barca negra...

De plomo el mar.

Los forzados sollozan:

¡Esta condena

no va a acabar!

La barca, la barca negra...

De ágata el mar.

Los forzados aúllan,

crujen los remos,

solloza el mar.

La barca, la barca negra...

Ébano el mar.

Los mástiles rechinan.

La barca negra

se va a acabar

La barca, la barca negra...

se hunde en el mar,

los galeotes cantan,

rompen amarras...

¡Bendito el mar!

La barca, la barca negra

no está en el mar;

ni están los galeotes

ni las cadenas...

¡Bendito el mar! 
Pero hay también en su espíritu claridades de sol. También sus ojos cansados recogen el alma verde de los campos del Norte y saben de la parda pincelada del rancho en la colina o del cuerpo bronceado y repleto, como fruta en sazón, de la campesina de las viejas tierras de la conquista.

Dice por ejemplọ:

Como un enfermo, reclinado buscando apoyo en el parrón, se tiende el rancho, en el milagro de las montañas y del sol.

O bien :

\author{
Un trozo \\ de tierra morena, \\ esponjoso y blando \\ es tu rostro. \\ Un fruto \\ que se comba rojo, \\ maduro $\mathrm{y}$ fragante, \\ es tu labio. \\ Tus ojos \\ tienen la negrura \\ del monte, de noche. \\ Tus ojos... \\ Tus largas pestañas \\ son como las sombras \\ que en la noche bajan \\ sobre la montaña. \\ Cisterna \\ henchida de ritmo, \\ tus fuertes $y$ suaves \\ caderas, \\ y tú, campesina, \\ toda eres un salmo, \\ un salmo que canta \\ a la Vida!
}

La cordillera de la costa, rica fuente en la Colonia de los mejores árboles de Chile, explotada por los astilleros jesuítas durante dos siglos, muestra sus lomos desnudos, donde sólo la viña pone en los veranos el verdegay de sus pámpanos nutridos. Raquíticas espigas se mueren de sed en sus faldas, donde rojea la arcilla. Zorros hambrientos persiguen a las majadas de cabros. Jotes enlutados ciernen su vuelo sobre los ranchos misérrimos. La tierra se quema bajo el sol; y mira pasar, sedienta, el agua de un gran río que va hacia el océano, como deseoso de abandonar cuanto antes las estériles montañas. 
En una tonalidad elegíaca, que deriva de Jorge González seguramente, Max Jara ha hecho, en un romancero sabio, el elogio de las tierras pobres. No figuran en él héroes legendarios, como en las antiguas gestas de España. Tampoco se exaltan episodios enormes. El árbol que, enredado entre los hervidores borbotones de la corriente, va hacia el mar, el quebranto del viajero sentado junto a los sauces acogedores, la niña morena como una espiga madurada en el estío, el gemido de las zurzulitas o el galope de la guerra civil de Concepción al Maule en los viejos tiempos de la formación de la República, a toda esta decoración lejana y simple, en un paisaje simple y cercano, le ha dado el poeta forma y carácter.

Leeré el romance El ArbolMuerto, hondo símbolo del destino, de puro sabor clásico, a pesar de la chilenidad de su asunto:

Camino del mar va el árbol, ayer, no más, florecido; solo, con las turbias aguas, muerto se lo lleva el río. Lo ha amortajado de espuma, $\mathrm{y}$ con un ronco alarido le va rezando, sin tregua, un responso sin motivo, en que, al mismo tiempo, dice la soberbia de ser río.

Camino del mar se va; ojos humanos lo han visto.

Cúbrenlo, a veces, las ondas;

y un largo reflejo lívido resbala, entonces, con ellas, en una fuga sin ruido; pero luego, con un brusco, resonante escalof río, corta la línea del aire sobre las aguas erguido; Las raíces poderosas destilando espeso limo, retorcidas y crispadas por un esfuerzo de siglos, ¡qué valió su vano arraigo ante la fuerza del sino! Frescas a un las heridas de los muñones macizos que fueron las ramas, vástagos recios, elásticos, finos, otros tantos brazos hábiles en los vientos suspendidos, que al morir en la desnuda verde luz del brote tímido tienen la belleza frágil de los dedos de los niños. 
Camino del mar va el árbol; nadie lo ha reconocido. ¡Quién lo viera en la montaña junto a la cuna del río! iQué atrás se quedara el mundo! Para otros el prodigio susurrante del follaje, y los vértigos floridos, y el orgullo de los frutos, y el secreto de los nidos.

Hoy ya todo le es ajeno, aun el propio destino.

A veces, entre aguas muertas, encuentra el tronco un asilo:

viscosas algas lo cubren, cual lo decoraran vivo bellezas de enredaderas en amores fugitivos.

Lento se hunde en el fango cual si estuviera dormido. Con el viento, pasa el tiempo y su imperceptible ritmo va royendo cada fibra mientras lo mece, tranquilo.

Pero un día, el sol lejano, la nube lluviosa vino, y el tronco entrará de nuevo en el turbion amarillo, cual una fuerza extraviada orientándose al destino; mas ya sin masa, al acaso derivando carcomido, sigue camino del mar sin nobleza de vencido.

Entre tanto, allá en el ancho y luminoso vacío, ebrios de vientos salados, rasgan el mar los navíos, o se yerguen, indolentes, con portentoso equilibrio, cada mástil trepidante al esfuerzo contenido; y las entrañas del mar los sienten pasar divinos, mientras los alumbran, altos, los viejos astros solícitos.

$\mathrm{Ya}$ en las velas, obedientes, trabaja el viento sumiso, cantando como otros días junto a la cuna del río; 
cual aún siguen cantando, con un vasto arranque lírico, entre el pueblo de los robles de la montaña, los hijos tal vez de ese mismo tronco que llega el mar, su destino, sobre un tumulto de espumas, florecimiento tardío, cual sobre un lecho de angustias, como un cadáver tendido.

De los agrios terrones costeros es también Jerónimo Lagos Lisboa, pero en su poesía no hay esta aspereza, de pura estirpe chilena que vemos en González Bastías y en Max Jara. Un lejano ascendiente portugués ha dado a su poesía nostalgiosa un sabor lunar de saudade, de ternura dulce y soledosa. Ved cómo se mezclan, por una hábil yuxtaposición de las imágenes, lo concreto y lo imaginado, lo sensorial y lo especulativo. Los años beben en una fuente, las violetas aroman nostalgias, una claridad lunar convalece en un blanco lecho de ternura. Germen de estilización, mezcla de lo concreto y de lo abstracto, que más tarde se convierte en un juego de acrobacia en los vanguardistas y pasa por una etapa de curioso estrabismo metafórico en Pablo de Rokha, Vicente Huidobro y Pablo Neruda.

Veamos un ejemplo:

¿Los diáfanos quince años de mi madre bebieron

en qué fontana grávida de estrellas? ¿Qué rosal

hizo sangrar sus manos? ¿Cuáles violetas dieron

aroma a sus nostalgias? ¿Qué claridad lunar

convaleció en el lecho blanco de su ternura?-

Tu vaso, madre mía, fué nardo y emoción.

Llenó tu vaso el viento de pena y de frescura

y lo volcó en mi lumbre genésica el amor.

De olorosa llovizna mi corazón va henchido, y hundida en él, cual viejo puñal, la flor de lis de mi estirpe, se curva. Bajo su arco florido van pasando los siglos sin hollar la raíz.

Hay en tal estilización un matiz curioso, pero que se reproduce en la evolución del sentido de la naturaleza en todas las literaturas del mundo. El poeta culto, dueño ya de todos los medios de expresión, abandona sus temas cortesanos, frívolos o cerebrales y vuelve con unción en su sensibilidad a un recuerdo juvenil, a un incón de montaña, a la visión de una escena entrevista al pasar por un camino o simplemente oye resonar en su memoria la voz de los vientos o la sinfonía de las corrientes. Vibra en esta interpretación trovadoresca el cansancio del hombre urbano, atormentado por la lucha diaria, por los ruidos 
de la gran ciudad, por la complicada red de pasiones que el íntimo contacto social hace nacer en la carne viva de su sensibilidad. Vuélvese, como un respiro, hacia lo sencillo, hacia lo puro, hacia el aire libre de las campiñas. Se idealiza a la mujer aldeana o campesina y se le agregan cualidades que el poeta quisiera encontrar en las mujeres de la ciudad.

Carlos Préndez Saldías, poeta eminentemente ciudadano, cultivado, más que por exceso de lecturas, por natural refinamiento de raza, ha dado en este sentido las notas más vivas, más frescas. Del simple erotismo, exceso de vida, de juventud, hasta la estilización en que se funde la idealidad del poeta con el aire de la sierra o de los campos.

Algo de madrigal y de elegía, de color y de emoción hay en esta composición Paslora, de su libro Peregrino del ansia, que recuerda las Vaqueiras castellanas de don Iñigo López de Mendoza, en pleno siglo XX.

Trae una brisa liviana
desde los cerros la aurora.
Es tan fresca la mañana
como tus brazos, pastora.
Porque el sol abre su lino
tiembla el rocío en los pastos.
Así, temblando, adivino
tus pequeños senos castos.
Está el campo de rastrojos
en su larga espera ardiente,
y más lo queman tus ojos
de lindo azul transparente.
No vayas por tus senderos
hacia los montes, pastora,
ven a olvidar tus corderos
y tu vertiente sonora
con mis labios forasteros
que tiñó tu zarzamora.

Esta compenetración del espíritu del poeta con la naturaleza puede también transformarse en un animismo o en un panteísmo elemental. $\mathrm{Ni}$ interpretación ni estilización. Tampoco embriaguez de color. $\mathrm{Ni}$ pretexto para contar con personales emociones. Es un nihilismo espiritual donde está fundida la conciencia. $\mathrm{Ni}$ alma ni materia.

Y más la piedra dura porque esa ya no siente.

(Darío.)

Ser el pobre arroyuelo que se evapora al sol. 
Ernesto Guzmân y Manuel Rojas representan, en aspectos de su poesía, este renunciamiento que es algo así como la antesala del vanguardismo. La naturaleza actúa en ellos en forma diversa, Guzmán, más cerebral que Rojas, trata de absorber la naturaleza. Animar lo que no tiene alma.

La pisada sea blanda y piadosa, peregrinos, por que no se lastimen los caminos.

Gracias porque mis ojos están nuevos todavía
mi cuerpo está liviano.
Gracias por este blando sacramento
de ponerme a vagar y que es amparo.
Gracias por el verdor que me recibe
con unciosa acogida y que me llama;
gracias por los caminos que me invaden
y me confortan en mi acción humana.

En Rojas el fenómeno es diferente. No intenta beberse la naturaleza, disolverla en su alma. Es él quien desea desaparecer en la vida natural: ser pastor, ser agua, ser flor o.fuente, diluírse en el trémolo cristalino de su chorro.

Así se ve en su Canción de Otoño;

Bajo este sol de Otoño, amarillo y sereno, he sentido unos dulces deseos de ser bueno. Deseos de ser otro más humilde, más grave; ansias de reencarnarme. Y de ser como el suave sándalo que perfuma el filo de las hachas que convierten su tronco en tiras y en hilachas.

¿Por aué será? No sé. Pero siempre bendigo la caricia bendita de este solcito amigo que ha vertido en mi alma enferma y dolorida un chorro perfumado con ansias y con vida...

$\mathrm{Y}$ por un caminito, lentamente, sereno, con la serenidad dentro del corazón, me he ido caminando, sintiéndome más bueno, bajo el beso tan tibio y tan suave del sol.

II

Ansias de reencarnarme. De ser un campesino humilde como un grano de trigo o de centeno y en la paz de la tarde, sentado en el camino, sentirse más de uno porque se es más bueno.

Deseos de ser otro. De ser algún pastor, manso, tranquilo y fuerte. $\mathrm{Y}$ guiando el ganado, 
ir tocando en las flautas pastorales de amor s haciendo un ramillete con las flores del prado.

Y de ser como el agua. Y de ser como el viento.

$O$ de ser una flor. O bien ser una fuente

y en un parque sombrío ir, momento a momento, muriendo en el murmullo del chorro transparente.

\section{III}

¡He sentido unas ansias de ser otro conmigo y ser otro con todos! Y de ser más sereno.

¿Qué queréis? Es tan tibio este solcito amigo. Y esta tarde tan triste. $Y$ este Otoño tan bueno.

Llegamos, por último, a la etapa más acendrada de esta estilización. La imaginación que, en el romanticismo, era una fuerza desbocada, una loca de la casa, es hoy inteligente. Aun más, armada de sabiduría. El idioma se retuerce y se complica bajo la presión cada vez más vigorosa de la técnica; crujen los huesos de la sintaxis, pero el idioma sale de sus viejos moldes y busca nuevos cauces donde precipitarse. A pesar de este cerebralismo, la naturaleza juega un papel importante en los poetas de vanguardia. Unense en ellos lo abstracto y lo concreto, sin un lazo visible y gramatical. Es el cubismo de la sintaxis. Metáforas y símiles son aristas decoradas de luces y de sombras, pero en todo este acumulamiento de tropos, pacientemente elaborados, hay una conciencia artística que crea y se adelanta a los tiempos. Un adaptarse a las estridencias de la época, cascabeleo de jazz y gritos inarticulados. Los motivos de color son patacones de pintura o rayas de carbón que recuerdan estampas primitivas o dibujos infantiles. El mundo inanimado despierta de su modorra y vive y ama como un hombre o como una mujer. La arbitraria medida del verso es una disonancia de Stravinski.

Los dos Pablos, Pablo de Rokha y Pablo Neruda, representan esta extrema estilización de la modalidad vanguardista en Chile, pero por sobre los malabarismos de su métrica antojadiza, hay una real emoción humana. Esto salva sus mayores extravagancias. Da a su poesía un carácter de grito, de sublevación, de un eterno elevarse hacia el espíritu; pero no es este el momento de explicar el secreto de su emoción. En esta larga sucesión de intérpretes de la naturaleza tienen también su lugar.

Pablo de Rokha, que en su afán de renovarlo todo ha renovado hasta la castiza palabra roca, escribiendola con $k$ y una $h$ interpolada que habrá hecho fruncir el ceño al doctor Oroz, tiene, en sus aciertos, muy numerosos, un alto sentido racial. 
Es el épico del vanguardismo. $\mathrm{Y}$ es, sobre todo, eminentemente chileno.

Voy a daros a conocer una Canción de las Tierras Chilenas, donde hay un profundo sentido nacionalista.

Claros los astros de diamante, dolorosa la tierra arada, y el mar como un árbol sonante, o lo mismo que un gran cantante parado encima de la nada. Un cinturón de cordilleras le ciñe los huesos profundos; cabellera de sementeras, y el cielo como una bandera clavada en la proa del mundo. Murmuran los vinos violentos en las tinajas del pasado; el sur le azota con los vientos; su sol es como un monumento al ideal crucificado.

Viejos de pueblos y vihuelas, oloroso a naranjas rubias, ingenuo como las escuelas, con inviernos llenos de abuelas y grandes ladridos de lluvias. Los caminos aventureros cruzan la cara del paisaje, tal una hilera de viajeros; el canto de los carreteros es como un carro de forraje. Ceñido de gentes valientes, la majada clara y madura levanta sus cantos hirvientes. Cien soles frutales $y$ ardientes alimentan la agricultura. $\mathrm{Y}$ anchas ciudades al concreto en la pollera de los ríos; allá un boldo como un soneto, o un peumo como un toro inquieto hacia las vacas del vacío. Ferrocarriles y guitarras trenzados sobre el campo inmóvil a la orilla de las cigarras; y el gesto animal de las parras cayendo sobre el automóvil. Va la hembra chilena vistiendo reflejos de melancolía; flor de cordura y sangre ardiendo, el cielo la viene siguiendo desde el otro lado del día. Puñaladas y valdivianos, toronjiles y damajuanas, y la cueca profunda, hermanos; 
los jaguares americanos

bramando sobre la mañana.

En el Crepusculario de Neruda hay una viva intervención del paisaje del sur de Chile. De la frontera es él. Ya conocen ustedes su Sinfonía de la trilla. Oigan ahora estos Aromos de Loncoche, amigos del poeta, de este poeta que es un corazón del cielo vacío y una palabra de este paisaje muerto. Neruda es el lírico de las escuelas nuevas.

La pata gris del Malo piś estas pardas tierras, hirió estos dulces surcos, movió estos curvos montes, rasguñó las llanuras guardadas por la hilera rural de las derechas alamedas bifrontes. El terraplén yacente removió su cansancio, se abrió como una mano desesperada el cerro, en cabalgatas ebrias cabalgaban las nubes arrancando de Dios, de la tierra y del cielo.

El agua entró en la tierra, mientras la tierra huía, abiertas las entrañas y anegada la frente; hacia los cuatro vientos en las tardes malditas, rodaban, ululando como tigres, los trenes, Yo soy una palabra de este paisaje muerto, yo soy el corazón de este cielo vacío;

cuando voy por los campos, con el alma en el viento, mis venas continúan el rumor de los ríos. ¿A dónde vas, ahora? Sobre el cielo la greda del crepúsculo, para los dedos de la noche. No alumbrarán estrellas. A mis ojos se enredan aromos rubios en los campos de Loncoche.

Al finalizar esta exposición en que he intentado demostrar cómo los poetas chilenos han sentido la naturaleza de su tierra, es preciso agregar algunas ideas más. Desde luego, que Chile es el único país de América que posee un núcleo de poetas intérpretes de sus distintas regiones. Antonio Borquez Solar ha recordado en muchas poesías su isla natal, pero más como un motivo de decoración que con verdadera emoción del panorama isleño. Roberto Meza Fuentes, nacido en Chiloé, canta los paisajes de sus islas o evoca sus viejas leyendas en el cristal armonioso de sus versos. Rubén Azócar ha vivido algunos años en las islas. Las conoce como si hubiera nacido en ellas; y el alma de sus colinas, el sabor de los vientos salinos y el ensueño de los poblachos de madera, orlados por la risa de espuma de las crecientes o el sollozo de las vaciantes, rompe las aiistas de sus versos modernos con un encanto de lejanía y tradición. Faltan poetas de la región austral, de Magallanes. Accidentalmente la han interpretado Gabriela Mistral y Pedro Prado, en motivos aislados, pájaros o árboles. 
Chile es un paisaje, dijo el Conde K.eyserling; por eso, la naturaleza es en la poesía y debe ser en la novela y el cuento una aspiración fundamental. Chile es un país de rincones, agrego yo, por eso sus poetas tiene sus características regionales que en Argentina no se ven. Allí la interpretación de la naturaleza ha derivado hacia el folklore gauchesco que en nosotros se ve raramente. Allí el motivo es uno, la inmensa pampa, océano de tierra parda abrazado con el cielo. Aquí los motivos son innumerables, porque cada valle, cada rincón son diversos. Por lo mismo, es imposible una novela de toda la raza, como en Argentina. Muchas novelas han de ser la novela de Chile. El esfuerzo del novelista es, entre nosotros, de una épica responsabilidad. 